Article

\title{
Impact of Energy Conservation and Emissions Reduction Policy Means Coordination on Economic Growth: Quantitative Evidence from China
}

\author{
Guoxing Zhang ${ }^{1,2,3}$, Zhenhua Zhang ${ }^{1, *}$, Xiulin Gao ${ }^{1}$, Lean $\mathrm{Yu}^{4}$, Shouyang Wang ${ }^{3}$ and \\ Yingluo Wang ${ }^{2}$ \\ 1 School of Management, Lanzhou University, Lanzhou 730000, China; \\ guoxingzh@lzu.edu.cn (G.Z.); gaoxllzu@163.com (X.G.) \\ 2 School of Management, Xi'an Jiaotong University, Xi'an 710049, China; ylwang@mail.xjtu.edu.cn \\ 3 Academy of Mathematics and Systems Science, Chinese Academy of Sciences, Beijing 100190, China; \\ sywang@amss.ac.cn \\ 4 School of Economics and Management, Beijing University of Chemical Technology, Beijing 100029, China; \\ yulean@amss.ac.cn \\ * Correspondence: zhangzh_10@lzu.edu.cn
}

Academic Editors: Guowei Hua, T. C. Edwin Cheng, Feng Chen, Shouyang Wang and Marc A. Rosen Received: 8 December 2016; Accepted: 22 April 2017; Published: 26 April 2017

\begin{abstract}
To understand the general relationship between Energy Conservation and Emissions Reduction (ECER) policy means coordination (PMC) and economic growth, this paper quantitatively investigates the impact on economic growth of differing PMCs. ECER policies from 1978 to 2013 in China are quantified across two dimensions of policy power and policy means, and then, PMC degrees are designed as independent variables and incorporated into a modified Cobb-Douglas production model. While determining the cointegration relationships by using a unit root test, a cointegration test and a stability test, cointegration equation is conducted by using quantitative data to explore the economic growth effects of PMC in China. The government's use of PMC in China is also analyzed and ranked. The empirical results show that there is a long-term cointegration relationship among the variables from 1978 to 2013. Additionally, the effects of the different PMCs on economic growth show significant discrepancies and each PMC usage ranking is also found to be significantly different, thereby implying that the use of different PMCs by the Chinese government needs to be further perfected.
\end{abstract}

Keywords: policy quantification; policy means coordination; economic growth; energy conservation and emissions reduction

\section{Introduction}

Energy Conservation and Emissions Reduction (ECER) has become a global goal, and many countries and organizations have conducted technological, engineering, policy and economic research to promote ECER in developing countries [1]. In reality, ECER has become a crucial national policy in China [2]. The Chinese regulation CPG (2006) [3], which first proposed the ECER concept, set the goal that energy consumption per unit of GDP should be reduced by $20 \%$ and the total discharge of major pollutants should be reduced by $10 \%$ during the period of the 11thfive-year plan. CPG (2012) [4] stated that by $2015, \mathrm{CO}_{2}$ emissions per unit of GDP were required to be reduced by $17 \%$ from 2010 levels. According to the two above regulations, this paper considers ECER policies to be those focused on energy conservation, water conservation, $\mathrm{SO}_{2}$ and $\mathrm{CO}_{2}$ emissions reduction and the comprehensive utilization of industrial solid waste. 
As the largest developing country in the world, China has become the world's largest consumer of energy and the world's largest emitter of $\mathrm{SO}_{2}$. Faced with the serious situation of ECER, dire energy supply shortages and increasing environmental pollution have made it challenging to maintain sustainable economic growth in China. If China wants to achieve sustainable economic development, ECER must be enforced [5]. Even though a series of ECER policies and measures has been enacted since the late 1970s, the current state is still far from the desired goals outlined in the ECER objectives. Significant improvements are required to standardize systems and government policies for full ECER implementation. However, ECER cannot be achieved through market mechanisms alone [6]. The government must enforce ECER implementation through the promulgation of effective policies. As ECER crosses multiple areas, ECER policies are beyond the boundaries of a single policy area or the responsibilities of an individual government agency. If a single policy is overemphasized, it may have detrimental effects on sustainable economic development. Therefore, to achieve better results, different policy means need to be coordinated when implementing ECER [7].

According to traditional neoclassical economic theory, in order to achieve the goal of ECER, the implementation of ECER policies will inevitably bring negative impact on economic growth [8]. However, according to the environmental Porter hypothesis, ECER policies will not increase the cost of production, but can stimulate business innovation, resulting in an increase in environmental technology efficiency and a further increase in corporate output [9], which will eventually promote economic growth, leading to win-win results between ECER and economic growth [10]. Based on the above two points of view, it is necessary for us to analyze which PMCs in ECER promote economic growth, and which PMCs in ECER hinder economic growth.

The rest of this paper is organized as follows. Section 2 presents the review of the present literature on policy coordination and ECER policies; Section 3 describes the methods of policy quantization, selected variables, modified model and methodology used in this paper. Section 4 reports on the results of a unit root test, cointegration test and stability test with estimated cointegration equation. Section 5 discusses the differences between usage rankings for policy means coordination (PMC) and consequent effect on economic growth. Section 6 presents the major conclusions and policy implications.

\section{Literature Review}

Present ECER policy studies in China have focused mainly on dealing with existing ECER policy implementation problems and solutions (Yuan et al. [11]; Zhao et al. [12]; Zhao and Ortolano [13]), evaluating the effect and policy welfare in ECER policies (Fang et al. [14]; Geng et al. [15]; Price et al. [16]), discussing the potential and actual costs of ECER under different policy scenarios, and determining optimum ECER implementation (Wang et al. [17]; Hao et al. [18]; Xi et al. [19]), investigating the key factors, departments and areas that influence the effect of the ECER and making policy suggestions according to those factors (Zhu et al. [20]; Fujii et al. [21]; Zhang et al. [22]), and outlining ECER policies in other countries and discussing the implications and references for China (Hu and Monroy [23]; Tanaka [24]; Yuan et al. [25]). These studies have relied on discussions about object, content, significance, effect, or the future direction of one group or one class of ECER policies, and most took a logical and analytical approach. Because of policy uncertainty and subjectivity, imbalances in levels of political power, and supply and demand levels, some policies may not function coherently, thereby reducing the effectiveness of ECER. To date, however, there have been few studies on policy coordination in ECER field.

There are plenty of studies researching policy coordination from at least four various aspects: definition, necessity, functions and department coordination. About the definition of policy coordination, Mulford and Rogers [26] defined policy coordination as a joint process between two or more organizations dealing with similar tasks which develops new rules or uses existing decision rules; Meijers and Stead [27] saw policy coordination as the management of multiple policies from multiple functional areas, or the management of the multiple aspects of a single functional area; Rostaing [28] stated that policy coordination has three coordination dimensions: "horizontal," "vertical" 
and "time," respectively; there are also two levels: "policy conformity" and "policy integration," respectively. As for the necessity of policy coordination, Camarero and Tamarit [29] postulated that policy coordination was required in situations in which there was conflict or competition between the policy objectives; Herzog [30] examined the necessity of international policy coordination issues when dealing with common international problems; Hughes et al. [31] pointed out that coordination between policy formulation and evaluation needs to be efficient and consistent. About the functions of policy coordination, Hoel [32] concluded that positive policy coordination can be beneficial to improve policy implementation efficiency to achieve a Pareto optimal state; Lee et al. [7] found that mixed policy coordination was more effective than using a single policy coordination approach; Effective policy coordination has been shown to achieve a greater level of performance [33] and create greater benefits [34]. As for department coordination, Iglesias et al. [35] pointed out that governments need to coordinate different departments when formulating public policies to balance the possible conflicts of interest between them; Vakili and Khorsandi [36] suggested that to improve policy implementation, policy coordination must be strengthened among the government, public welfare organizations, and nongovernment organizations; Huang et al. [37] analyzed different organizations and frameworks for Chinese innovation policies, and emphasized that policy development also needed to be coordinated. These policy coordination studies have discussed the importance and superiority of policy coordination mainly from a policy effectiveness perspective, which has shown that policy coordination is of great importance to successful policy implementation and the achievement of social and economic goals. As governments begin to pay increasing attention to PMC, dealing with the coordination between the different policies means is likely to become one of the greatest policy formulation challenges in the future. However, they have focused less on policy content and the PMC effect on economic growth.

Starting from the method of quantitative content analysis of Krippendorff [38], many policy studies have investigated policy content. Srebotnjak [39] conducted a quantitative investigation into the environment policy objectives of Canada and Japan. Cools et al. [40] conducted a quantitative analysis on Flemish transport policy means. Zhang et al. [41] investigated Chinese industries to measure the institutional factors affecting enterprise ECER based on several indexes. These quantitative studies have further motivated the policy documents quantization in this paper. Once PMC in ECER field can be studied from a policy content perspective, the results could be used to guide ECER policy formulation in China. Therefore, it is imperative to focus on policy content when seeking to elaborate on PMC and the effect on economic growth, so that the findings can assist governments in using PMC to promote economic growth in the process of ECER.

Analysis models of institutional policy have been used in the academic studies. Eggertsson [42] introduced institutional policy factors into the Cobb-Douglas production function and proposed a production function which included capital, labor and policy factors. Bjorn and Danny [43] also introduced institutional policy factors into the $\mathrm{Cobb}$-Douglas production function, and analyzed the effect of these factors on financial globalization. It can thus be seen that introducing policy factors into the Cobb-Douglas production function has become a normative research paradigm. PMC based on policy document quantization is introduced into the Cobb-Douglas production function, which will require some innovation.

As economic growth is still the main focus in China because of the current relatively low income per capita and the low urbanization rate, sustainable economic development requires the Chinese government to promote PMC vigorously in the ECER field. Institutional PMC has significant effects on economic growth in the process of implementing ECER. Clarifying how PMC in the ECER field affects economic growth can assist in ensuring constant improvements in the ECER policy system, while maintaining stable economic development. The negative effect of PMC on economic growth indicates the government's economic cost when they use different PMC methods to promote ECER. Therefore, the implementation of an improved ECER at a less economic cost is a problem that needs to be urgently addressed by government officials, which is the primary motivation for this study. 


\section{Methods}

\subsection{Policy Quantization}

As the policies formulated by the Chinese government are not only related to policy means, but are also involved with departmental levels and policy types (e.g., the effectiveness of the policies issued by the State Council are higher than those issued by ministries), this paper attempts to quantify ECER policies from the dimensions of policy power and policy means based on a definition and collection of ECER policies in China.

\subsubsection{Policy Collection}

In order to start from the policy documents content to discuss the ECER policy coordination effects on economic growth comprehensively, this research collected all ECER policies from the Chinese central government (the National People's Congress, State Council and Ministries under the State Council, etc.) from 1978 to 2013 which could be found in Global Laws and Regulations Database (GLRD) (2016) [44]. To guarantee the comprehensiveness and accuracy of the policy data, the policies were checked and filtered according to the Wan Fang Database (WFD) (2016) [45], the China Law and Reference by Wolters Kluwer(CLRWK) [46] and the official websites of the Chinese central government. The Chinese government has promulgated thousands of policies to promote ECER since 1978: CPG (1979) [47] and CPG (1997) [48] are amongst them. By searching all the relevant keywords, the research team collected ECER policy documents one by one in the combination methods of electronic search and manual retrieval from the above databases, taking nearly one month to collect them. Eventually 4142 policies related to ECER were collected. According to the ECER policy definitions, we first selected 2636 highly relevant ECER policies. Then, we read these policies intensively from the aspects of policy background, formulating departments, formulation time, policy types, policy means and policy objectives. After the lengthy process of classification and selection, the ECER policy database was established, which contained 1195 ECER policies which had been promulgated independently or jointly by more than 40 departments, such as the National People's Congress and the State Council of the People's Republic of China, the Environmental Protection Department, the Ministry of Industry and Information Technology, the National Development and Reform Commission, the Ministry of Housing and Urban-Rural Development, the Ministry of Finance, the Ministry of Transport, the State Administration of Taxation, the Ministry of Agriculture, the Ministry of Science and Technology, the China Banking Regulatory Commission, the Ministry of Education, Organization Affairs Administration under the State Council and the State Administration for Industry and Commerce.

\subsubsection{Quantitative Criteria}

To measure the PMC degree from the policy content itself, this paper qualified the ECER policies from the two dimensions of policy power and policy means. Based on the research of Libecap [49], policy power refers to the index which reflects the legal effect of the policies and which was based on a detailed study of CPG (2002) [50] issued by the State Council as well as suggestions from relevant legal experts [51]. Depending on the policy type and the level of the department promulgating the ECER policies, numerical values from 5 to 1 were given to indicate the policy power (Table 1). The policy power qualification scores were considered as follows: the higher the leadership department level, the higher the legal effectiveness of the policy (e.g., laws formulated by the National People's Congress). From the investigation of the ECER policies, it was found that the higher the department level, the more macro policies there were, while the behavioral subject constraints were less transparent. As a result, the policy means scores were all relatively low. Although lower-level departments issue policies which have lesser legal effects (such as those issued by ministries), the effects on the behavioral subject constraints were generally clearer, so the policy means received higher scores. The superposition 
of the two directions made up for any defects in the policy content validity reflected by a single quantitative indicator.

Table 1. Quantitative criteria for Energy Conservation and Emissions Reduction (ECER) policy power in China.

\begin{tabular}{cl}
\hline Scores of Policy Power & \multicolumn{1}{c}{ Quantitative Criterion } \\
\hline 5 & Laws promulgated by the Committee of the National People's Congress (NPC). \\
\hline 4 & $\begin{array}{l}\text { Command of ministries; directives and regulations promulgated by the } \\
\text { State Council. }\end{array}$ \\
\hline 3 & $\begin{array}{l}\text { The provisional regulations and provisions, plans, decisions, opinions, } \\
\text { measures and standards promulgated by the State Council; rules, } \\
\text { regulations and decisions issued by Ministries. }\end{array}$ \\
\hline 2 & $\begin{array}{l}\text { The opinions, methods, schemes, guidelines, regulations, rules, conditions and } \\
\text { standards issued by Ministries. }\end{array}$ \\
\hline 1 & Notices, announcements and planning. \\
\hline
\end{tabular}

Policy means are a method of achieving an established purpose when a government formulates and implements policies. Murphy et al. [52] found that the main means used to improve energy efficiency by the government of the Netherlands' were energy performance certificates, laws and regulations, economic means, such as loans, energy taxes, covenant and information tools. Zhang et al. [41] found that the ECER policies in Chinese iron, steel and chemical industries were mainly focused on laws and regulations, tax policies, credit policies and government subsidies. The classification of these policies facilitated the analysis in this paper. Through an intensive reading of 1195 policies, policy content coding and a combination of ECER policy expert recommendations, we divided the main ECER policy means into several categories: administrative means, fiscal and tax means, financial means, personnel means, and guidance means. Quantification was conducted by assigning numerical values from 5 to 1 according to the detail degree and the enforcement level. There are only scores at 5, 3 and 1 points as the quantitative criteria. A quantitative criteria score of 4 points is between 5 points and 3 points; and the quantitative criteria score of 2 points is between 3 points and 1 point. The particular policy means can be assigned to 4 points (or 2 points) when the quantifiers thought that the detail level or enforcement level of the particular policy means was better than 3 points (or 1 points), but did not reach 5 points (or 3 points) [53]. The quantitative criteria are shown in Appendix A (Table A1).

\subsubsection{Validity and Reliability of Quantitative Process}

After determining the ECER policy quantitative criteria, we qualified the policies by training personnel through several rounds of scoring from different groups. To ensure that the quantitative results could reflect reality, feasibility and accuracy, 20 policy researchers scored the ECER policies. The researchers were put into 10 groups to score each policy so as to reduce the influence of subjective factors and ensure a consistency in the scoring results. If there were multiple means to be found in a policy while scoring, scores were given based on the quantitative criteria.

There were six steps in the quantitative process. First, each quantitative criterion was explained in detail to the scoring personnel and a discussion was conducted to answer questions from the scoring personnel and modify the criteria until all scoring personnel fully understood the quantitative criteria. After training, as a preliminary, the scoring personnel scored 10 randomly selected policies. As the results were not ideal after comparing the results with each member, we discussed and analyzed the causes for the differences again and further optimized the quantitative criteria. Third, after the quantitative criteria were optimized, the scoring personnel again scored10 additional randomly selected policies. The results indicated that the directional consistency (i.e., the policy means scoring 
result trends are consistent, but the values are different, e.g., if the score is 1 or 3 , it tends toward the same direction; if the score is 1 or 4 , there is a directional conflict) of the means scores was $88.57 \%$, and for those policies in which the score results indicated directional conflicts, we discussed and further improved the quantitative criteria. The fourth step was the formal scoring stage in which each scoring personnel scored 598 policies that had been allocated in advance. Comparative analyses of the scoring results showed that the directional consistency for the policy means scores was $92.30 \%$, indicating an obvious improvement after the training and pre-scoring step. In the fifth step, we again scored those policies in which the score results from the fourth step indicated directional conflict, and invited two ECER policy research professors and two National Development and Reform Commission policy researchers to examine scoring results of the policy means. In the sixth step, to determine the final policy means quantitative results, we calculated the arithmetical average of the 10 groups of scoring results.

The research methods above ensured the validity and reliability of the quantitative results and also could ensure the research conclusions would meet the scientific research requirements [51]. Therefore, in this paper, quantifying the ECER policies using policy power and policy means ratings not only elucidated policy content validity, but also guaranteed policy coordination degree measurement rationality.

\subsection{Variables and Data Descriptions}

\subsubsection{Independent Variables}

In our analysis, the PMC degree in each year is utilized as the independent variable. PMC degree is used to describe the degree of how a policy's multiple means work together. Generally speaking, the greater the policy power is, the more specific policy means there will be, thus achieving better coordination. Therefore, $P M C$ degree is calculated by multiplying the policy power score by the policy means score. The expression of this kind of combination can be shown by the multiplication effects. The formula used is Equation (1):

$$
\text { PMC degree }_{t}=\sum_{j=1}^{N} P P_{j} \times P M_{j k} \times P M_{j l} k \neq l, t=[1978,2013]
$$

where $P M C$ degree $_{t}$ denotes the ECER policy means coordination degree in year $t ; N$ denotes the total policies in year $t ; P P_{j}$ denotes the policy power score of policy $j ; P M_{j k}$ and $P M_{j l}$ denote the scores for policy means $k$ and $l$ for policy $j . k$ and $l(k \neq l)$ denote two different means selected from five means; administrative means, fiscal and tax means, financial means, personnel means and guidance means.

The number of policies using administrative means, fiscal and tax means, financial means, personnel means and guidance means were 1138, 326, 56, 305 and 727, respectively. Given that the administrative means is the most frequently used in China's ECER policies from 1978 to 2013, we focused on the coordination between the administrative means and other means. Four combinations or types of PMC are identified, the specific names for which are listed in Table 2, along with the other variables.

Table 2. Definition and calculation of the variables.

\begin{tabular}{ccl}
\hline Definition & Variables & \multicolumn{1}{c}{ Calculation } \\
\hline Dependent variable & LnGDP & Logarithm of each year's GDP calculated from1978 constant prices \\
\hline \multirow{3}{*}{ Controlling variables } & LnK & Logarithm of capital stock calculated from 1978 constant prices per year \\
& LnL & Logarithm of the number of employed people per year \\
& LnT & Logarithm of the technological advancement per year \\
\hline \multirow{4}{*}{ Independent variables } & LnCAT & Logarithm of coordination between administrative means and fiscal and tax means \\
& LnCAF & Logarithm of coordination between administrative means and financial means \\
& LnCAP & Logarithm of coordination between administrative means and personnel means \\
& LnCAG & Logarithm of coordination between administrative means and guidance means \\
\hline
\end{tabular}




\subsubsection{Dependent Variable and Controlling Variables}

All values related with price are computed by using 1978 constant prices. To analyze the effect of PMC on economic growth, each year's GDP (million) from 1978 to 2013 is utilized as the dependent variable; the capital stock (million), the number of employed people (million people) and the technological advancement from 1978 to 2013 are utilized as the controlling variables. In addition, we use the price index to adjust the GDP data in China Statistical Yearbook (CSY) (2014) [54] to obtain the annual GDP (1978 constant prices), and the perpetual inventory method (PIM) proposed in Holz [55] to estimate the capital stock per year (1978 constant prices). The number of employed people per year is also taken from CSY (2014) [54]. The technological advancement is described by total factor productivity (TFP) which is calculated by Solow residual method of Solow [56].

\subsubsection{Data Descriptions}

Table 3 shows the results for the variables' descriptive statistics. As can be seen in the standard deviation values for $\operatorname{Ln} G D P, \operatorname{Ln} K, \operatorname{Ln} L$, and $\operatorname{Ln} T$, the deviation in each variable is small, indicating that the annual growth in GDP, capital stock $(K)$, employed people $(L)$ and technological advancement $(T)$ are relatively steady from 1978 to 2013. However, the results for the PMC degree (taking the logarithm) show that the largest average value is $4.863(\operatorname{LnCAG})$, the minimum average value is $2.010(\operatorname{LnCAF})$, the maximum Std. Dev value is 2.138 (LnCAF), and the minimum Std. Dev value is 1.043 (LnCAP). In addition, there is also a significant difference between the maximum and minimum PMC degree values, and the average value and Std. Dev values. This illustrates that the usage degree of the different PMCs vary in the Chinese government for certain periods while the usage degree for the same PMC is different in each period.

Table 3. Descriptive statistics.

\begin{tabular}{cccccc}
\hline Variable & $\boldsymbol{N}$ & Minimum & Maximum & Mean & Std. Dev. \\
\hline LnGDP & 36 & 8.201 & 11.463 & 9.821 & 1.002 \\
LnK & 36 & 8.672 & 12.460 & 10.394 & 1.148 \\
LnL & 36 & 10.600 & 11.251 & 11.044 & 0.214 \\
LnT & 36 & 0.350 & 0.560 & 0.469 & 0.066 \\
LnCAT & 36 & 1.001 & 6.309 & 3.831 & 1.363 \\
LnCAF & 36 & -4.605 & 4.904 & 2.010 & 2.138 \\
LnCAP & 36 & 0.940 & 6.551 & 4.533 & 1.043 \\
LnCAG & 36 & 1.856 & 6.839 & 4.836 & 1.195 \\
\hline
\end{tabular}

\subsection{Modified Cobb-Douglas Production Model}

As the paper mainly focused on the effect of PMC on economic growth, economic growth is considered to be related not only to the policy factors, but also to capital, labor factors and technological advancement. Therefore, we refer to Bjorn and Danny [43], and introduce different PMCs into the $\mathrm{Cobb}$-Douglas production function to build a modified Cobb-Douglas production model that allows for an analysis of the effect of PMC on economic growth as Equation (2):

$$
\begin{gathered}
Y_{t}=F\left(K_{t}, L_{t}, T_{t}, \text { PMC degree }_{t}, u_{t}\right)=A_{t} K_{t}^{\alpha} L_{t}^{\tau} T_{t}^{\gamma}\left(\text { PMC degree }_{t}\right)^{\beta} u_{t} \\
t \in[1978,2013]
\end{gathered}
$$

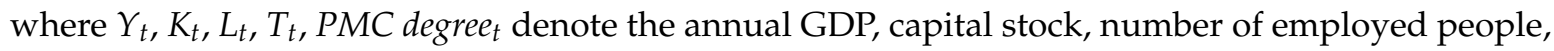
technological advancement and the ECER policy means coordination degree, respectively.

Taking the logarithm on both sides of Equation (2), we have Equation (3):

$$
\operatorname{Ln} Y_{t}=\operatorname{Ln} A_{t}+\alpha \operatorname{Ln} K_{t}+\xi \operatorname{Ln} L_{t}+\gamma \operatorname{Ln} T_{t}+\beta \operatorname{Ln}(P M C \text { degree })_{t}+\operatorname{Ln} u_{t} t \in[1978,2013]
$$


where $\operatorname{Ln} A_{t}$ is a parameter denoted by $C_{t}$ below; $\alpha, \xi, \gamma$ and $\beta$ denote the elasticity of $K_{t}, L_{t}, T_{t}$ and $P M C$ degree $_{t}$ respectively, and $\operatorname{Ln} u_{t}$ denotes a random error term, denoted by $\varepsilon_{t}$ below.

Here, we focus on the effect on economic growth of coordination between the administrative means and other means. The model for PMC degree based on Equation (3) is specified as Equation (4):

$$
\begin{aligned}
\operatorname{LnGDP} P_{t} & =C+\alpha \operatorname{Ln} K_{t}+\xi \operatorname{Ln} L_{t}+\gamma \operatorname{Ln} T_{t}+\beta_{1} \operatorname{Ln} C A T_{t} \\
& +\beta_{2} \operatorname{Ln} C A F_{t}+\beta_{3} \operatorname{Ln} C A P_{t}+\beta_{4} \operatorname{LnC} A G_{t}+\varepsilon_{t}
\end{aligned} t \in[1978,2013]
$$

where GDP and $K_{t}$ denote gross domestic product and capital stock calculated using 1978 constant prices in year $t$, respectively. $L_{t}$ means the number of employed people in year $t$, and $T_{t}$ means the technological advancement. $C A T_{t}, \ldots, C A G_{t}$ denote the PMC degree in year $t ; \alpha, \xi$ and $\gamma$ denote the coefficients for the controlling variables; $\beta_{a}(a=1,2,3,4)$ denotes the coefficients for the independent variables; $C$ denotes the constants in the model; and $\varepsilon_{t}$ means the random error terms.

The relationship between GDP and capital stock, the number of employed people, technological advancement and the PMC degree described by the modified Cobb-Douglas production model in Equation (4) indicates that these variables may change together in the long term [57]. Therefore, there may be a long-term equilibrium relationship among the variables, which can be tested by using a unit root test calculation, the Johansen-Juselius cointegration test and a cointegration equation [58].

\subsection{Methodology}

\subsubsection{Unit Root Test}

As in Sims [59], this study used an unrestricted vector autoregressive (VAR) model. To examine the properties of all variables, we first conduct the unit root test. The augmented Dickey-Fuller (ADF) test [60] is chosen to ensure robust results.

To test the unit-root hypothesis, the following ADF test form is used:

$$
\Delta y_{t}=\alpha y_{t-1}+\sum_{i=1}^{k} \beta_{i} \Delta y_{t-i}+X_{t}^{i} \gamma+\mu_{t}
$$

where $y$ is the variable being examined by the unit root test in period $t ; \Delta$ is the first difference operator, so $\Delta y_{t-1}$ denotes $y_{t-1}-y_{t-2} ; X_{t}^{i}$ is an exogenous variable with a constant or a constant trend; and $\mu_{t}$ is the i.i.d. error term with the meaning $=0$ and variance $=\sigma^{2}$.

To test the null hypothesis for the existing unit root in $y_{t}$, the null hypothesis $\alpha=0$ is tested in Equation (5). If $\alpha$ is significantly less than zero, the null hypothesis for the presence of a unit root will be rejected. Therefore, the ADF test is used in this study to ensure that there is a comprehensive stationary time series measurement.

\subsubsection{Cointegration and Model Stability}

If a time series is non-stationary, while its $d$ th difference is stationary, then we can say it is integrated by an order of $d$, which is written as $I(d)$. In this case, the presence of the cointegration relationship can be tested. Johansen-Juselius test (Johansen and Juselius [61]; Johansen [62]), which has maximum eigenvalue statistics and trace statistics, can be used to detect the existence of cointegration among multiple variables.

The maximum eigenvalue statistics are conducted by calculating the maximum likelihood test statistics $\lambda_{\max }$ with an assumption of existing $\mathrm{r}$ cointegration vectors. The maximum eigenvalue test is computed as follows:

$$
\lambda_{\max }=-T \log \left(1-K_{r+1}\right)
$$

where $T$ denotes the sample size, and $K_{r+1}$ is the eigenvalue. 
Trace statistics are conducted by calculating the likelihood test statistics $\lambda_{\max }$ with the assumption that there are fewer than $r$ cointegrating vectors. The trace statistics are written as Equation (7):

$$
\lambda_{\max }=-T \sum_{i=r+1}^{n} \log \left(1-K_{i}\right)
$$

where $T$ denotes the sample size, and the null hypothesis goes to $r=g$.

Since a low freedom degree and small sample size may influence the parameter estimation validity in the VAR model, it is essential to examine the model's robustness. Model misspecification or parameter non-constancy can have a severe negative influence on inferences which would result in incorrect conclusions [57]. In this study, we use the characteristic roots of the coefficient matrix to test the model's stability [63]. If the characteristic roots have a modulus less than one, the model is deemed robust.

\section{Empirical Results}

\subsection{Results of Unit Root Test}

Since the unit root test is used to examine the stationary properties of the variables, the ADF test and PP test are discussed in this part. The results of the two unit root tests for all the variables in terms of both level and difference forms are shown in Table 4.

Table 4. Results of unit root test.

\begin{tabular}{ccc}
\hline \multirow{2}{*}{ Series } & \multicolumn{2}{c}{ ADF Test } \\
\cline { 2 - 3 } & C & C and T \\
\hline LnGDP & 0.191 & -2.338 \\
LnK & 5.994 & -0.859 \\
LnL & -2.581 & -0.739 \\
LnT & -2.006 & -2.327 \\
LnCAT & -2.148 & -2.311 \\
LnCAF & -2.077 & -3.099 \\
LnCAP & -1.768 & -2.774 \\
LnCAG & -1.641 & -3.201 \\
$\Delta \operatorname{Ln} G D P$ & $-4.266^{* * *}$ & $-4.162^{* *}$ \\
$\Delta \operatorname{Ln} K$ & $-2.688^{*}$ & $-4.526^{* * *}$ \\
$\Delta \operatorname{Ln} L$ & $-4.926^{* * *}$ & $-6.230^{* * *}$ \\
$\Delta \operatorname{LnT}$ & $-4.244^{* * *}$ & $-4.693^{* * *}$ \\
$\Delta \operatorname{Ln} C A T$ & $-7.164^{* * *}$ & $-6.649^{* * *}$ \\
$\Delta \operatorname{Ln} C A F$ & $-7.531^{* * *}$ & $-7.402^{* * *}$ \\
$\Delta \operatorname{Ln} C A P$ & $-12.186^{* * *}$ & $-12.186^{* * *}$ \\
$\Delta \operatorname{Ln} C A G$ & $-6.691^{* * *}$ & $-6.587^{* * *}$
\end{tabular}

Note: $\Delta$ indicates a time series in first difference. ${ }^{* * *},{ }^{* *}$ and ${ }^{*}$ indicates the rejection of the null hypothesis at $1 \%$, $5 \%$ and $10 \%$. The critical value for the ADF test with constant $(\mathrm{C})$ and with constant and trending $(\mathrm{C}$ and $\mathrm{T})$ at the $1 \%, 5 \%$ and $10 \%$ levels of significance were $-3.646,-2.954,-2.616$ and $-4.263,-3.553,-3.210$.

As shown in Table 4, the ADF test results, both constant and constant and trending, indicate that all the variables were non-stationary in level but stationary in the first difference, with a rejection of the null hypothesis for the existence of a unit root of at least 10\%. Because the first difference forms for all variables are stationary, we proceed to select the lag intervals for the VAR model.

\subsection{Lag Intervals for the Vector Autoregressive (VAR) Model}

To analyze the cointegration relationship of the variables in the VAR model, we need to select an optimal lag interval. As shown in Table 5, a lag interval of 2 is adopted from the results of the sequential modified LR test statistic (LR), the final prediction error(FPE), the Akaike information 
criterion (AIC)and the Hannan-Quinn information criterion (HQ), even though a lag interval of 1isdetermined from the results of the Schwarz information criterion (SC).

Table 5. VAR lag selection criteria ${ }^{a}$.

\begin{tabular}{ccccccc}
\hline Lag & LogL & LR & FPE & AIC & SC & HQ \\
\hline 0 & 90.24995 & NA & $1.09 \times 10^{-12}$ & -4.838233 & -4.479089 & -4.715754 \\
1 & 395.3951 & 448.7429 & $8.38 \times 10^{-19}$ & -19.02324 & $-15.79095 *$ & -17.92094 \\
2 & 507.9676 & $12.5725 * \mathrm{~b}$ & $9.56 \times 10^{-20 *}$ & $-21.88045^{*}$ & -15.77501 & $-19.79832^{*}$ \\
\hline
\end{tabular}

Note: a Endogenous variables: $\operatorname{Ln} G D P, \operatorname{Ln} K, \operatorname{Ln} L, \operatorname{Ln} T, \operatorname{Ln} C A T, \operatorname{LnCAF,~LnCAP,~LnCAG;~exogenous~variables:~C;~}$ sample: 1978-2013. ${ }^{\mathrm{b}}$ The sign of * denotes lag order selected by the criterion.

\subsection{Cointegration Equation}

Trace statistics and maximum eigenvalue statistics are used to estimate the number of cointegration relationships and develop a cointegration equation with normalized cointegrating

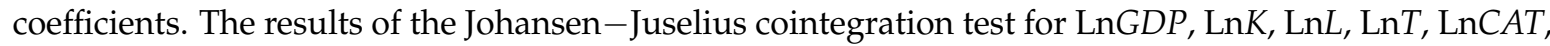
LnCAF, LnCAP and LnCAG are presented in Table 6. The trace statistics test indicates that the existence of the hypotheses of zero, one, two and three cointegration equations is rejected at a $5 \%$ level of significance, but the existence of the hypothesis of four cointegration equations is accepted at the same significance level. In addition, the maximum eigenvalue statistics test shows a rejection for the existence of a hypothesis of zero, one and two cointegration equations at a $5 \%$ level of significance, but accepts an existence for a hypothesis of three cointegration equations at same significance level.

Table 6. Results of Johansen-Juselius cointegration test.

\begin{tabular}{ccccc}
\hline Hypothesized No. of CE(s) $^{\mathbf{a}}$ & Eigenvalue & Trace Statistic & $\mathbf{0 . 0 5}$ Critical Value & Prob. $^{* *, d}$ \\
\hline None $^{*, c}$ & 0.941973 & 298.496800 & 169.599100 & 0.0000 \\
At most 1 & 0.893818 & 201.704200 & 134.678000 & 0.0000 \\
At most 2 & 0.736574 & 125.455700 & 103.847300 & 0.0009 \\
At most 3 & 0.587534 & 80.100370 & 76.972770 & 0.0283 \\
At most 4 & 0.392891 & 49.989930 & 54.079040 & 0.1103 \\
At most 5 & 0.359197 & 33.022340 & 35.192750 & 0.0842 \\
At most 6 & 0.285373 & 17.891200 & 20.261840 & 0.1026 \\
At most 7 & 0.173220 & 6.467368 & 9.164546 & 0.1576 \\
\hline Hypothesized No. of CE(s) ${ }^{\text {b }}$ & Eigenvalue & Max-Eigen Statistic & $\mathbf{0 . 0 5}$ Critical Value & Prob. ${ }^{* *}$ \\
\hline None * & 0.941973 & 96.792580 & 53.187840 & 0.0000 \\
At most 1 * & 0.893818 & 76.248450 & 47.078970 & 00.0000 \\
At most 2 & 0.736574 & 45.355380 & 40.956800 & 0.0150 \\
At most 3 & 0.587534 & 30.110440 & 34.805870 & 0.1635 \\
At most 4 & 0.392891 & 16.967590 & 28.588080 & 0.6635 \\
At most 5 & 0.359197 & 15.131150 & 22.299620 & 0.3643 \\
At most 6 & 0.285373 & 11.423830 & 15.892100 & 0.2220 \\
At most 7 & 0.173220 & 6.467368 & 9.164546 & 0.1576 \\
\hline
\end{tabular}

Notes: ${ }^{\mathrm{a}}$ Trace test indicated four cointegrating equation(s) at the 0.05 level. ${ }^{\mathrm{b}}$ Max-eigenvalue test indicated 3 cointegrating equation(s) at the 0.05 level. ${ }^{\mathrm{c}}$ The sign of ${ }^{*}$ denotes rejection of the hypothesis at the 0.05 level.

$\mathrm{d}$ The sign of ${ }^{* *}$ indicates MacKinnon-Haug-Michelis [64] $p$-values.

To be consistent with reality, we need to choose a cointegration equation that is meaningful in economics [65]. There is only one cointegration equation in which the coefficients for $\operatorname{Ln} K, \operatorname{Ln} L$ and LnT have positive signs. Therefore, we select the cointegration equation with normalized cointegrating coefficients to obtain a better explanation. 
From the normalized cointegrating coefficients listed in Table 7, the cointegration equation is as follows:

$$
\begin{aligned}
\operatorname{Ln} G D P= & -1.8201+0.7346 \operatorname{Ln} K+0.2787 \operatorname{Ln} L+2.3471 \operatorname{Ln} T-0.0207 \operatorname{Ln} C A T \\
& +0.0122 \operatorname{Ln} C A F+0.0137 \operatorname{LnC} A P-0.0369 \operatorname{Ln} C A G(-0.0053) \\
& (-0.0159)(-0.1149)(-0.0017)(-0.0010)(-0.0033)(-0.0032)
\end{aligned}
$$

where the values in parentheses denote standard errors.

Several conclusions can be drawn about economic growth in China from the above standardized cointegration Equation (8).

Firstly, Equation (8) shows that there is a long-term cointegration relationship between the variables discussed previously from 1978 to 2013. Secondly, the coefficients of LnK, LnL and LnT are all positive, which is consistent with the reality of the economic situation. Thirdly, the coefficients of LnCAF and LnCAP are all positive, which indicates that a $1 \%$ increment in CAF and CAP led to a $0.0122 \%$ and $0.0137 \%$ increment in GDP in the ECER field. Finally, the coefficients of LnCAT, and LnCAG are all negative, which illustrates that a $1 \%$ increment in $C A T$, and $C A G$ leads to a $0.0207 \%$ and $0.0369 \%$ decrement in GDP in the ECER field.

Table 7. Cointegrating Equation ${ }^{\mathrm{a}}$.

\begin{tabular}{ccccccccc}
\hline LnGDP & Ln $\boldsymbol{L}$ & $\operatorname{Ln} \boldsymbol{L}$ & $\mathbf{L n} \boldsymbol{T}$ & $\mathbf{L n C A T}$ & $\mathbf{L n C A F}$ & $\operatorname{LnCAP}$ & $\operatorname{LnCAG}$ & $\boldsymbol{C}$ \\
\hline \multirow{2}{*}{1} & -0.7346 & -0.2787 & -2.3471 & 0.0207 & -0.0122 & -0.0137 & 0.0369 & 1.8201 \\
& $(-0.0053)^{\mathrm{b}}$ & $(-0.0159)$ & $(-0.1149)$ & $(-0.0017)$ & $(-0.0010)$ & $(-0.0033)$ & $(-0.0032)$ & $(-0.1511)$ \\
\hline
\end{tabular}

Notes: ${ }^{\mathrm{a}}$ Log likelihood: $407.1155 .{ }^{\mathrm{b}}$ Normalized cointegrating coefficients (standard error in parentheses).

\subsection{Stability Test for the VAR Model}

The stability of the VAR model needs to be checked and the estimated parameters need to be tested whether they changed over time or not. The VAR roots of the characteristic polynomial derived from Table 8 demonstrate that no root lay outside the unit circle [63]. The estimated Equation (8) in this paper is found to be robust through conducting the stability test for the VAR model. That is to say, the VAR model and the estimated parameters listed previously satisfy the model stability condition.

Table 8. Vector Autoregressive (VAR) roots for the characteristic polynomial.

\begin{tabular}{cc}
\hline Root & Modulus \\
\hline 0.998633 & 0.998633 \\
$0.950397-0.124081 \mathrm{i}$ & 0.958462 \\
$0.950397+0.124081 \mathrm{i}$ & 0.958462 \\
$0.380531-0.232286 \mathrm{i}$ & 0.445826 \\
$0.380531+0.232286 \mathrm{i}$ & 0.445826 \\
0.143443 & 0.143443 \\
$-0.104298-0.036221 \mathrm{i}$ & 0.110408 \\
$-0.104298+0.036221 \mathrm{i}$ & 0.110408
\end{tabular}

Notes: No root lies outside the unit circle. VAR satisfies the stability condition.

\section{Discussions}

\subsection{Analysis of Cointegration Equation Results}

Table 7 shows the estimated cointegration equation results for the effect the administrative means and other means coordination had on economic growth. The controlling variables of capital stock $(K)$, employed people $(L)$ and technological advancement $(T)$ have significantly positive effects on GDP. The coefficients of $K, L$ and $T$ are the largest of all the variable coefficients, which is consistent 
with reality, illustrating that the estimated results are able to better explain the variables in a real-life situation. Specific statements can be concluded as follows.

The coordination between administrative means and fiscal and tax means (LnCAT) has a significantly negative effect on economic growth. The reason for this is that the government offered ECER subsidies or tax incentives, which inevitably reduces government investment in other areas, thereby somewhat reducing economic output. The government mainly uses the coordination of fiscal and tax means and administrative means, which infers excessive government intervention in the ECER guidance process, thereby reducing the guidance role of the fiscal and tax means, which is not conducive to economic growth.

The coordination between administrative means and financial means (LnCAF) has a significantly positive effect on economic growth, which indicates that as long as the government increases coordination between financial means and administrative means at the ECER policy level, both ECER policy objectives and economic growth can be realized at the same time.

The coordination between administrative means and personnel means (LnCAP) has a significantly positive effect on economic growth. This denotes that increasing the penalties for offenders and increasing the cultivation or training of talent have important significance for the promotion of economic growth and ECER. At the same time, it also shows that at the ECER policy level, the government can realize greater ECER compliance while promoting economic growth by increasing the coordination between the personnel means and the administrative means. As the ECER pressure gradually increases, this should be the first choice for the Chinese government, which could promote ECER under the "Strategy of Strengthening the Country on Human Resource Development (2002)" [66] to increase the coordination between the personnel means and administrative means.

The coordination between administrative means and guidance means ( $\mathrm{LnCAG}$ ) has a significantly negative effect on economic growth. This may be related to the imperfect use of the administrative means and guidance means by the Chinese government, which indicates that at the ECER policy level, the government pays a higher economic cost when promoting ECER through administrative means and guidance means coordination.

Through the above analysis, it can be seen that there are two kinds of effects on economic growth for different PMCs. For one thing, the administrative means and financial means coordination (LnCAF) and the administrative means and personnel means coordination (LnCAP) have significantly positive effects on economic growth, which demonstrate that when formulating ECER policy, the above two PMCs should be used to promote ECER and economic growth at the same time. For the other thing, the administrative means and fiscal and tax means coordination (LnCAT) and the administrative means and guidance means coordination ( $\mathrm{LnCAG}$ ) have significantly negative effects on economic growth, which show that when formulating ECER policy, the above two PMCs can be used to slow down economic growth so as to promote ECER.

In a word, these economic effects demonstrate two kinds of explanation for PMC. On one hand, the effect of the PMC on economic growth reflects the influence on economic development when a certain type of PMC is used by the government in ECER policy formulation. On the other hand, it also reflects the economic cost when the government uses more severe PMC to promote ECER.

\subsection{Discussions on Usage Ranking and Policy Means Coordination (PMC) Effects}

Table 9 presents the difference between the usage rankings and effects on economic growth for PMC of ECER policies in China from 1978 to 2013. Based on Equation (1), the PMC degree for a policy is calculated by using the policy's power score multiplied by the policy means score. The PMC degree per year is calculated by using the sum of the corresponding PMC degree. Therefore, the higher a policy's PMC degree, the higher the Chinese government's use of the PMC. 
Table 9. Differences between usage ranking and effect on economic growth.

\begin{tabular}{cccc}
\hline Variable & Mean & Usage Ranking & Effect \\
\hline LnCAT & 3.831 & 3 & $\mathrm{~N}$ \\
LnCAF & 2.010 & 4 & $\mathrm{P}$ \\
LnCAP & 4.533 & 2 & $\mathrm{P}$ \\
LnCAG & 4.836 & 1 & $\mathrm{~N}$ \\
\hline
\end{tabular}

Notes: source: collated by the author according to Tables 4-8. Usage ranking is ranked according to the mean value of policy means coordination degree. $\mathrm{P}$ or $\mathrm{N}$ denotes that the variable has a "significantly positive" or "significantly negative" effect on economic growth.

As shown in Table 9, the administrative means together with the fiscal and tax means, financial means, personnel means and guidance means are coordinated differently, which demonstrate that the Chinese government has used various policy means to promote ECER by the method of PMC at the ECER policy level. Specifically, in the ECER policies from 1978 to 2013, the Chinese

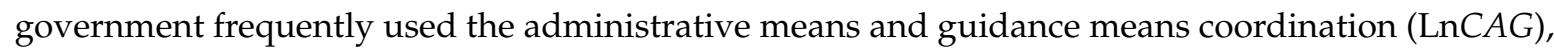
the administrative means and personnel means coordination $(\operatorname{LnCAP})$, and the administrative means and fiscal and tax means coordination (LnCAT); however, use of the administrative means and financial means coordination (LnCAF) was less frequent.

According to the comparisons between different economic effects and various usage rankings, several findings can be shown as follows. First, the administrative means and personnel means coordination ( $\mathrm{LnCAP}$ ) has positive effects on economic growth, and is also frequently used by the government (the usage ranking of 2 nd), which illustrates that training and educating people are the main means the Chinese government uses to deal with the implementation of the "Strategy of Developing the Country by Science and Education (1995)" [67] and the "Strategy of Strengthening the Country on Human Resource Development (2002)" [66].

Second, the administrative means and fiscal and tax means coordination (LnCAT) and the administrative means and guidance means coordination ( $\mathrm{LnCAG}$ ) have significant negative effects on economic growth, but the government tends to use these frequently (usage rankings of 3rd and 1st, respectively). The government's excessive administrative intervention in ECER has hindered economic growth, especially when using fiscal and tax means or guidance means at the same time.

Third, while the administrative means and financial means coordination (LnCAF) significantly promoted economic growth, the use from the government is the least frequent (4th place). This fact illustrates that the Chinese government has not yet grasped the essence of the use of financial means when seeking to promote both ECER and economic growth, showing that the Chinese government has a certain blindness in their frequent use of PMC.

In summary, there are two ways to read the results of comparisons between different economic effects and various usage rankings. From the standpoint of policy means, first of all, the Chinese government is supposed to think about which kinds of policy means should be adopted since the economic growth development trends are expected to remain unchanged in China over the long term. Therefore, as pressure to both ensure consistent growth in the Chinese market economy and increase ECER compliance, the Chinese government is expected to increase the use of personnel means and especially financial means rather than rely on the use of other policy means in subsequent ECER policy formulation processes.

Second of all, when using PMC, the Chinese government should increase the administrative means and personnel means coordination (LnCAP), specifically the administrative means and financial means coordination (LnCAF), and reduce the administrative means and fiscal and tax means coordination (LnCAT) and especially the administrative means and guidance means coordination (LnCAG), so as to give full play to the basic role of economic leverage to ensure ECER compliance and extension. 


\section{Conclusions and Policy Implications}

Based on identifying the Energy Conservation and Emissions Reduction (ECER) policies formulated by the central Chinese government from 1978 to 2013 and quantifying them from two dimensions of policy power and policy means, this paper develops policy means coordination(PMC) degrees as independent variables which are incorporated into a modified Cobb-Douglas production model, and then conducts a cointegration equation to discuss the economic growth effects of PMC in China while determining the cointegration relationship using the unit root, cointegration and stability tests. Furthermore, this paper analyzes the government's PMC usage ranking in China based on the PMC in the ECER field. The main conclusions can be drawn as follows.

First of all, a long-term cointegration relationship is found among the eight variables of GDP, capital stock, employed people, technological advancement and coordination between administrative means and other means from 1978 to 2013. Enhancing capital stock, employed people and technological advancement is conducive to increasing GDP in China as expected in this paper, which illustrates the real-life situation that capital stock, employed people and technological advancement are three important factors affecting the growth of GDP.

Moreover, the effects of the different PMCs on economic growth are found to have significant discrepancies. For instance, the administrative means and financial means coordination and the administrative means and personnel means coordination have significant positive effects on economic growth, which have shown that the government can realize both ECER policy objectives and economic growth by increasing these two kinds of coordination. Meanwhile, the administrative means and fiscal and tax means coordination and the administrative means and guidance means coordination have significantly negative effects on economic growth because of the imperfect use of these two kinds of coordination.

Last but not least, the situation for each PMC is significantly different, thereby indicating that the usage ranking for each PMC is significantly different, also indicating that the Chinese government synthetically uses various policy means at the policy level to promote ECER by using PMC. In China's ECER policies from 1978 to 2013, the Chinese government uses the administrative means and guidance means coordination, the administrative means and personnel means coordination and the administrative means and fiscal and tax means coordination most frequently, but uses the administrative means and financial means coordination less frequently.

From these conclusions and the situation of PMC, some important policy implications can be summarized as follows. First and foremost, the Chinese government should think about adopting different means cautiously when implementing ECER through policies. Specifically, financial means and personnel means should be given more focus than guidance means and fiscal and tax means because of their different economic effects.

Second, the Chinese government is expected to further increase the use of the administrative means and financial means coordination which contributes to economic growth due to the comparisons between usage ranking and economic effect when the Chinese government implements ECER by applying policy different means at the same time. It has been demonstrated that using administrative means and financial means coordination and administrative means and personnel means coordination is conducive to economic growth while implementing ECER if administrative means and financial means coordination is used less than the administrative means and personnel means coordination.

Finally, the Chinese government is supposed to reduce the use of administrative means and fiscal and tax means coordination and the administrative means and guidance means coordination which are harmful to economic growth because of the comparisons between usage ranking and economic effect while implementing ECER by applying different policy means together. The fact which brings up the conflicts is that the administrative means and fiscal and tax means coordination and the administrative means and guidance means coordination are not conducive to economic growth, especially when these two kinds of coordination are used more frequently than the administrative means and financial means coordination. 
There are some limitations to this study, such as in the aspect of data feasibility. The data pool used in this paper mainly relied on national-level data, which may have a negative impact on the precision of the econometric results due to the lack of provincial-level data. Moreover, for the sake of brevity, this paper does not discuss the effect of all PMCs on economic growth. In the future, the authors will collect panel data at the provincial level to provide more explanations of the effects of other PMCs. This will be the focus of our later research, which will also use an econometric model.

Acknowledgments: We appreciate the comments from the experts from the Chinese Academy of Science and the anonymous referees. This research was supported by the National Natural Science Foundation of China (71103077, 91224001), Program for New Century Excellent Talents in University of Ministry of Education of China (NCET-13-0267), National Science Fund for Distinguished Young Scholars (NSFC No. 71025005), and Humanity and Social Science Plan Foundation of Ministry of Education of China (15YJA630097).

Author Contributions: Guoxing Zhang designed the research framework; Xiulin Gao and Lean Yu collected the data; Shouyang Wang and Yingluo Wang contributed analysis tools; Zhenhua Zhang performed the experiments and wrote the paper.

Conflicts of Interest: The authors declare no conflict of interest.

\section{Appendix A}

Table A1. Quantitative criteria for the ECER policy means in China.

\begin{tabular}{|c|c|}
\hline \multirow{2}{*}{ Score } & Means \\
\hline & Administrative Means \\
\hline 5 & $\begin{array}{l}\text { - Implement strict administrative approval and superior government control system for pollution } \\
\text { projects, strongly encourage energy conservation and delegate approval authority; } \\
\text { formulate enforceable access conditions, thresholds and standards; formulate assessment, } \\
\text { inspection and supervisory methods related to ECER; formulate directories for the mandatory } \\
\text { elimination of backward production capacity; strictly implement environmental impact } \\
\text { assessments for administrative approval projects; formulate a mandatory management approach } \\
\text { to specifically promote ECER, etc. }\end{array}$ \\
\hline 3 & $\begin{array}{l}\text { - Decentralize administrative approval authority and reduce approval process for pollution } \\
\text { control and energy conservation projects; explicitly require developing access conditions, } \\
\text { thresholds and standards; explicitly require the implementation of ECER assessment, } \\
\text { supervision and inspection; require strict implementation for the elimination of backward } \\
\text { production capacity and environmental impact assessments; explicitly require policies or } \\
\text { systems development promoting ECER; though notall relevant programs have not } \\
\text { been formulated. }\end{array}$ \\
\hline \multirow[t]{2}{*}{1} & $\begin{array}{l}\text { - Control from government is very loose for pollution prevention or energy conservation; } \\
\text { has mentioned above terms. }\end{array}$ \\
\hline & Guidance Means \\
\hline 5 & $\begin{array}{l}\text { - Vigorously guide individuals or enterprises to do activities related to ECER; have formulated } \\
\text { specific implementation measures or programs to propagate ECER compliance; have formulated } \\
\text { detailed recommended listsfor product consumption; have formulated approaches for the } \\
\text { implementation of demonstration or pilot projects; have formulated catalogs to promote product } \\
\text { technology; have formulated a detailed guidance system; have formulated other guidance } \\
\text { means related to ECER. }\end{array}$ \\
\hline 3 & $\begin{array}{l}\text { - Explicitly propose to vigorously implement propaganda and strengthen the implementation of } \\
\text { identity management for ECER; explicitly propose to formulate recommended product } \\
\text { consumption lists and implement demonstration projects; explicitly propose to formulate other } \\
\text { guidance means related to ECER; however, not all relevant programs or catalogs have } \\
\text { been formulated. }\end{array}$ \\
\hline 1 & - Just mentioned or related to the above terms. \\
\hline
\end{tabular}


Table A1. Cont.

\begin{tabular}{|c|c|}
\hline \multirow{2}{*}{ Score } & Means \\
\hline & Administrative Means \\
\hline \multicolumn{2}{|r|}{ Fiscal and Tax Means } \\
\hline 5 & $\begin{array}{l}\text { - Provide strong support in the budget, subsidies, grants, interest subsidies as well as awards and } \\
\text { have proposed support methods or the amount of financial assistance, subsidies, investment as } \\
\text { well as awards; provide strong tax incentives, clearly put forward a tax incentives catalog, } \\
\text { quota or have formulated preferential methods; have formulated methods of tax punishment for } \\
\text { violators; have formulated product catalogs or criteria for government procurement, etc. }\end{array}$ \\
\hline 3 & $\begin{array}{l}\text { - Clearly put forward strong support for ECER transformation and eliminated backward } \\
\text { production capacity in financial, tax and other aspects; clearly put forward increasing } \\
\text { government procurement efforts for ECER products and increasing government investment } \\
\text { efforts in ECER, though not all relevant support amounts have been put forward nor have all } \\
\text { relevant methods or catalogs been formulated. }\end{array}$ \\
\hline 1 & $\begin{array}{l}\text { - Just mentioned providing fiscal and tax means without formulating or nominating } \\
\text { relevant amounts. }\end{array}$ \\
\hline \multicolumn{2}{|r|}{ Personnel Means } \\
\hline 5 & $\begin{array}{l}\text { - Establish central specialized agencies to promote ECER and promote the mechanism; } \\
\text { maximize commendations for outstanding personnel and formulate a comprehensive method; } \\
\text { punish personnel for negligence or violation of the relevant provisions, and formulate specific } \\
\text { punishment methods; maximize personnel training, improve the level of treatment and } \\
\text { formulate systems related to the development of human resources; formulate performance } \\
\text { evaluation methods for personnel related with ECER and link the evaluation results with } \\
\text { promotion, appointment or dismissal. }\end{array}$ \\
\hline
\end{tabular}

- Clearly propose adding staff members to agencies related to ECER; strengthen leadership and clear the present agency personnel duties for ECER; increase education and training for relevant personnel; commend outstanding personnel, punish violators; assess the outcome of relevant personnel and then link the results of the evaluation and personnel performance together; however, have not yet formulated relevant commendations or punishments.

1 - Just mentioned the above terms.

\begin{tabular}{ll}
\hline \multicolumn{1}{c}{ - } & \multicolumn{1}{c}{ Financial Means } \\
\hline 5 & $\begin{array}{l}\text { Provide preferential credit for energy conservation and pollution reduction, and formulate } \\
\text { relevant support methods or support mechanisms; clearly require credit punishment for high } \\
\text { energy consumption and high polluting projects, formulate the project, amount, duration, } \\
\text { or system without giving a loan; improve credit policies related with ECER support and } \\
\text { formulate relevant credit methods. }\end{array}$ \\
\hline 3 & $\begin{array}{l}\text { Emphasize improvement in the ECER financial support policies; requirement for credit support } \\
\text { refusal for enterprises not meeting the national industrial requirements; establish a loan } \\
\text { punishment period for enterprises violating relevant regulations; strengthened supervision of } \\
\text { credit; but without formulating any related methods. }\end{array}$ \\
\hline 1 & - $\quad$ Just mentioned ECER promotion using financial means. \\
\hline
\end{tabular}

Notes: There are only scores at 5, 3 and 1 points as the quantitative criteria in this article. A quantitative criteria score of 4 points is between 5 points and 3 points; and the quantitative criteria score of 2 points is between 3 points and 1 point. 


\section{References}

1. Zhang, J.; Fu, M.; Geng, Y.; Tao, J. Energy saving and emission reduction: A project of coal-resource integration in Shanxi Province, China. Energy Policy 2011, 39, 3029-3032. [CrossRef]

2. Li, L.; Tan, Z.; Wang, J.; Xu, J.; Cai, C.; Hou, Y. Energy conservation and emission reduction policies for the electric power industry in China. Energy Policy 2011, 39, 3669-3679. [CrossRef]

3. The Central People's Government of the People's Republic of China (CPG). The National Economy and Social Development of the Eleventh Five-Year Plan Outline. 2006. Available online: http://www.gov.cn/ gongbao/content/2006/content_268766.htm (accessed on 1 December 2016). (In Chinese)

4. CPG. The Notice of Twelfth Five-Year Control Scheme for Greenhouse Gas Emissions Issued by the State Council. The Central People's Government of the People's Republic of China, 2012. Available online: http://www.gov.cn/zwgk/2012-01/13/content_2043645.htm (accessed on 1 December 2016). (In Chinese)

5. Wang, Q.; Chen, Y. Energy saving and emission reduction revolutionizing China's environmental protection. Renew. Sustain. Energy Rev. 2010, 14, 535-539. [CrossRef]

6. Coase, R.H. The problem of social cost. J. Law Econ. 1960, 3, 1-44. [CrossRef]

7. Lee, K.; Leung, J.Y.T.; Pinedo, M.L. Coordination mechanisms with hybrid local policies. Discret. Optim. 2011, 8, 513-524. [CrossRef]

8. Feichtinger, G.; Hartl, R.F.; Kort, P.M.; Veliov, V.M. Environmental policy, the porter hypothesis and the composition of capital: Effects of learning and technological progress. J. Environ. Econ. Manag. 2005, 50, 434-446. [CrossRef]

9. Porter, M.; Linde, C.V.D. Toward a New Conception of the Environment-Competitiveness Relationship. J. Econ. Perspect. 1995, 9, 97-118. [CrossRef]

10. Telle, K.; Larsson, L. Do Environmental regulations hamper productivity growth? How accounting for improvements of plants environmental performance can change the conclusion. Ecol. Econ. 2007, 61, 438-445. [CrossRef]

11. Yuan, J.; Kang, J.; Yu, C.; Hu, Z. Energy conservation and emissions reduction in China-Progress and prospective. Renew. Sustain. Energy Rev. 2011, 15, 4334-4347. [CrossRef]

12. Zhao, X.; Li, H.; Wu, L.; Qi, Y. Implementation of energy-saving policies in China: How local governments assisted industrial enterprises in achieving energy-saving targets. Energy Policy 2014, 66, 170-184. [CrossRef]

13. Zhao, X.; Ortolano, L. Implementing China's national energy conservation policies at state-owned electric power generation plants. Energy Policy 2010, 38, 6293-6306. [CrossRef]

14. Fang, G.; Tian, L.; Fu, M.; Sun, M. The impacts of carbon tax on energy intensity and economic growth-A dynamic evolution analysis on the case of China. Appl. Energy 2013, 110, 17-28. [CrossRef]

15. Geng, J.; Lu, Y.; Wang, T.; Giesy, J.P.; Chen, C. Effects of energy conservation in major energy-intensive industrial sectors on emissions of polychlorinated dibenzo-p-dioxins and polychlorinated dibenzofurans in China. Energy Policy 2010, 38, 2346-2356. [CrossRef]

16. Price, L.; Levine, M.D.; Zhou, N.; Fridley, D.; Aden, N.; Lu, H.; Mcneil, M.; Zhang, N.; Qin, T.; Yowargana, P. Assessment of China's energy-saving and emission-reduction accomplishments and opportunities during the 11th Five Year Plan. Energy Policy 2011, 39, 2165-2178. [CrossRef]

17. Wang, H.; Zhou, P.; Zhou, D.Q. Scenario-based energy efficiency and productivity in China: A non-radial directional distance function analysis. Energy Econ. 2013, 40, 795-803. [CrossRef]

18. Hao, H.; Wang, H.; Ouyang, M. Fuel conservation and GHG (Greenhouse gas) emissions mitigation scenarios for China's passenger vehicle fleet. Energy 2011, 36, 6520-6528. [CrossRef]

19. Xi, F.; Geng, Y.; Chen, X.; Zhang, Y.; Wang, X.; Xue, B.; Dong, H.; Liu, Z.; Ren, W.; Fujita, T.; et al. Contributing to local policy making on GHG emission reduction through inventorying and attribution: A case study of Shenyang, China. Energy Policy 2011, 39, 5999-6010. [CrossRef]

20. Zhu, Q.; Peng, X.; Wu, K. Calculation and decomposition of indirect carbon emissions from residential consumption in China based on the input-output model. Energy Policy 2012, 48, 618-626. [CrossRef]

21. Fujii, H.; Managi, S.; Kaneko, S. Decomposition analysis of air pollution abatement in China: Empirical study for ten industrial sectors from 1998 to 2009. J. Clean. Prod. 2013, 59, 22-31. [CrossRef]

22. Zhang, Y.J.; Liu, Z.; Zhang, H.; Tan, T.D. The impact of economic growth, industrial structure and urbanization on carbon emission intensity in China. Nat. Hazards 2014, 73, 579-595. [CrossRef] 
23. Hu, Y.; Monroy, C.R. Chinese energy and climate policies after Durban: Save the Kyoto Protocol. Renew. Sustain. Energy Rev. 2012, 16, 3243-3250. [CrossRef]

24. Tanaka, K. Review of policies and measures for energy efficiency in industry sector. Energy Policy 2011, 39, 6532-6550. [CrossRef]

25. Yuan, J.; Xu, Y.; Zhang, X.; Hu, Z.; Xu, M. China's 2020 clean energy target: Consistency, pathways and policy implications. Energy Policy 2014, 65, 692-700. [CrossRef]

26. Mulford, C.L.; Rogers, D.L. Definitions and Models; Iowa State University Press: Ames, IA, USA, 1982.

27. Meijers, E.; Stead, D. Policy Integration: What Does It Mean and How Can It Be Achieved? A Multi-Disciplinary Review. In Presented at the Berlin Conference on the Human Dimensions of Global Environmental Change: Greening of Policies-Interlinkages and Policy Integration, Berlin, Germany, 3 December 2004.

28. Rostaing, J.P. Building Policy Coherence: Tools and Tensions; OECD (The Organisation for Economic Co-operation and Development): Paris, France, 1996.

29. Camarero, M.; Tamarit, C. A rationale for macroeconomic policy coordination: Evidence based on the Spanish peseta. Eur. J. Political Econ. 1995, 11, 65-82. [CrossRef]

30. Herzog, B. Coordination of fiscal and monetary policy in CIS-countries: A theory of optimum fiscal area? Res. Int. Bus. Financ. 2006, 20, 256-274. [CrossRef]

31. Hughes, C.E.; Ritter, A.; Mabbitt, N. Drug policy coordination: Identifying and assessing dimensions of coordination. Int. J. Drug Policy 2013, 24, 244-250. [CrossRef] [PubMed]

32. Hoel, M. Coordination of environmental policy for transboundary environmental problems? J. Public Econ. 1997, 66, 199-224. [CrossRef]

33. Carley, S. Decarbonization of the U.S. electricity sector: Are state energy policy portfolios the solution? Energy Econ. 2011, 33, 1004-1023. [CrossRef]

34. Aronsson, T.; Wehke, S. Public goods, unemployment and policy coordination. Reg. Sci. Urban Econ. 2008, 38, 285-298. [CrossRef]

35. Iglesias, G.; del Río, P.; Dopico, J.Á. Policy analysis of authorization procedures for wind energy deployment in Spain. Energy Policy 2011, 39, 4067-4076. [CrossRef]

36. Vakili, G.; Khorsandi, S. Coordination of cooperation policies in a peer-to-peer system using swarm-based RL. J. Netw. Comput. Appl. 2012, 35, 713-722. [CrossRef]

37. Huang, C.; Amorim, C.; Spinoglio, M.; Gouveia, B.; Medina, A. Organization, programme and structure: An analysis of Chinese innovation policy framework. RED Manag. 2004, 34, 367-387.

38. Krippendorff, K. Content Analysis: An Introduction to Its Methodology, 2nd ed.; Sage: Thousand Oaks, CA, USA, 2004.

39. Srebotnjak, T. The role of environmental statisticians in environmental policy: The case of performance measurement. Environ. Sci. Policy 2007, 10, 405-418. [CrossRef]

40. Cools, M.; Brijs, K.; Tormans, H.; De Laender, J.; Wets, G. Optimizing the implementation of policy measures through social acceptance segmentation. Transp. Policy 2012, 22, 80-87. [CrossRef]

41. Zhang, Z.; Jin, X.; Yang, Q.; Zhang, Y. An empirical study on the institutional factors of energy conservation and emissions reduction: Evidence from listed companies in China. Energy Policy 2013, 57, 36-42. [CrossRef]

42. Eggertsson, P. Economic Behavior and Institutions: Principles of Neoinstitutional Economics; Cambridge University Press: Cambridge, UK, 1990.

43. Bjorn, V.C.; Danny, C. Multiple equilibria in the dynamics of financial globalization: The role of institutions. J. Int. Financ. Markets Instrum. Money 2012, 22, 329-342.

44. Global Laws and Regulations Database. 2016. Available online: http://policy.mofcom.gov.cn/service/claw. action (accessed on 1 December 2016). (In Chinese)

45. Wan Fang Database. 2016. Available online: http://c.wanfangdata.com.cn (accessed on 1 December 2016). (In Chinese)

46. China Law \& Reference by Wolters Kluwer. 2016. Available online: http:/ /law.wkinfo.com.cn (accessed on 1 December 2016). (In Chinese)

47. CPG. The Notice for Saving Oil. 1979. Available online: http://policy.mofcom.gov.cn/blank/claw!fetch. action?id=G000134366 (accessed on 1 December 2016). (In Chinese)

48. CPG. The Law of the People's Republic of China on Energy Conservation. 1997. Available online: http: / /www.gov.cn/flfg/2007--10/28/content_788493.htm (accessed on 1 December 2016). (In Chinese) 
49. Libecap, G.D. Economic variables and the development of the law: The case of western mineral rights. J. Econ. Hist. 1978, 38, 338-362. [CrossRef]

50. The Central People's Government of the People's Republic of China. Regulations on Procedures for the Formulation of Rules and Regulations. 2002. Available online: http://www.gov.cn/gongbao/content/2002/ content_61556.htm (accessed on 1 December 2016). (In Chinese)

51. Liao, Z. The evolution of wind energy policies in China (1995-2014): An analysis based on policy instruments. Renew. Sustain. Energy Rev. 2016, 56, 464-472. [CrossRef]

52. Murphy, L.; Meijer, F.; Visscher, H. A qualitative evaluation of policy instruments used to improve energy performance of existing private dwellings in the Netherlands. Energy Policy 2012, 45, 459-468. [CrossRef]

53. Zhang, G.; Zhang, Z.; Guan, X.; Fang, M. Is the synergy between measures and objectives of energy conservation and emission reduction policies in china effective? Based on the research of 1052 energy conservation and emission reduction policies. J. Manag. Sci. China 2017, 2, 161-181. (In Chinese).

54. China Statistical Yearbook. 2014. Available online: http://www.stats.gov.cn/tjsj/ndsj/2014/indexch.htm (accessed on 1 December 2016). (In Chinese)

55. Holz, C.A. New capital estimates for China. China Econ. Rev. 2006, 17, 142-185. [CrossRef]

56. Solow, R.M. Technical progress and the aggregate production function. Rev. Econ. Stat. 1957, 39, 312-320. [CrossRef]

57. Lin, B.; Zhang, G. Estimates of electricity saving potential in Chinese nonferrous metals industry. Energy Policy 2013, 60, 558-568. [CrossRef]

58. Ghali, K.H.; El-Sakka, M.I.T. Energy use and output growth in Canada: A multivariate cointegration analysis. Energy Econ. 2004, 26, 225-238. [CrossRef]

59. Sims, C.A. Macroeconomics and reality. Econometrica 1980, 48, 1-48. [CrossRef]

60. Dickey, D.A.; Fuller, W.A. Distribution of the estimators for autoregressive time series with a unit root. J. Am. Stat. Assoc. 1979, 74, 427-431. [CrossRef]

61. Johansen, S.; Juselius, K. Maximum likelihood estimation and inferences on cointegration with applications to the demand for money. Oxf. Bull. Econ. Stat. 1990, 52, 169-210. [CrossRef]

62. Johansen, S. Likelihood-Based Inference in Cointegrated Vector Autoregressive Models; Oxford University Press: Oxford, UK, 1995.

63. Lütkepohl, H. New Introduction to Multiple Time Series Analysis; Springer: Berlin, German, 2006.

64. MacKinnon, J.G.; Haug, A.A.; Michelis, L. Numerical distribution functions of likelihood ratio tests for cointegration. J. Appl. Econom. 1999, 14, 563-577. [CrossRef]

65. Hendry, D.F.; Juselius, K. Explaining cointegration analysis: Part II. Energy J. 2001, 22, 75-120. [CrossRef]

66. Strategy of Strengthening the Country on Human Resource Development (SSCHRD). 2002. Available online: http://news.xinhuanet.com/newscenter/2002-06/11/content_435834.htm (accessed on 1 December 2016). (In Chinese)

67. Strategy of Developing the Country by Science and Education (SDCSE). 1995. Available online: http: / / news.xinhuanet.com/misc/2006-01/07/content_4021977.htm (accessed on 1 December 2016). (In Chinese)

(C) 2017 by the authors. Licensee MDPI, Basel, Switzerland. This article is an open access article distributed under the terms and conditions of the Creative Commons Attribution (CC BY) license (http://creativecommons.org/licenses/by/4.0/). 